\title{
Gonoarthrosis in former athletes treated which regenerative therapy and therapeutic exercise program
}

\author{
(C) CrossMark \\ Lisbey Naranjo Abada, Viviana Romero Vidal ${ }^{\mathrm{b}}$, Hilda Rosa Rabilero Sabatés ${ }^{\mathrm{c}}$ \\ Manuscript submitted: 09 March 2020, Manuscript revised: 18 April 2020, Accepted for publication: 27 May 2020
}

\section{Corresponding Author ${ }^{\text {a }}$}

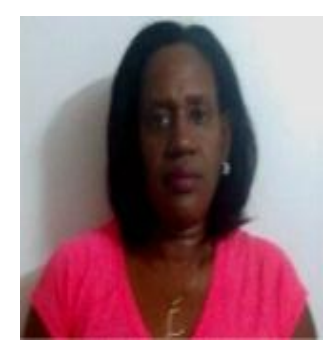

\section{Keywords}

exercises;

former athletes;

knee joint;

osteoarthrosis;

regenerative therapy;

\begin{abstract}
Osteoarthritis, or wear and tear of the knee joint, is a cause of sports trauma, affecting a large number of the population of former athletes in the province. The therapeutic alternative to gonoarthrosis exatlets implanted with regenerative therapy and rehabilitative exercises is applied to this sports-practicing population with balls. The assessment of variables, in responses to treatment implemented in the exathletes, was carried out over 6 months, where bilateral thigh atrophy prevailed over unilateral atrophy, to lesser degree atrophy of the affected thighs was presented after treatment with the applied therapeutic exercise program. $71.4 \%$ showed recovery of muscle strength with grade 5 (normal) muscle notes for the muscle group of knee flexor poplites, and $85.7 \%$ with grade 5 (normal) muscle notes for the femoral or crural quadriceps muscle group, which are involved in the extension of the knees. With the application of this exercise alternative in former athletes with gonoarthrosis treated with regenerative therapy, more than $70 \%$ showed recovery of the variables studied.
\end{abstract}

International Journal of Health Sciences (C) 2020. This is an open access article under the CC BY-NC-ND license (https://creativecommons.org/licenses/by-nc-nd/4.0/).

\section{Contents}

Abstract

1 Introduction.

2 Materials and Methods.

3 Results and Discussions...

4 Conclusion

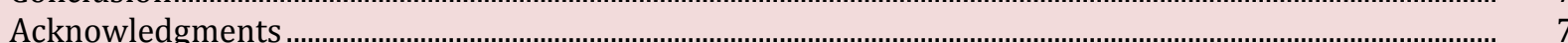

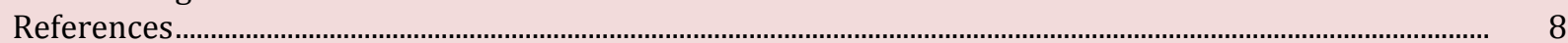

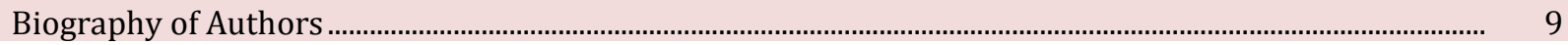

a Provincial Center of Sports Medicine, Santiago de Cuba, Cuba

b Provincial Center of Sports Medicine, Santiago de Cuba, Cuba

c University of the Orient, Santiago de Cuba, Cuba 


\section{Introduction}

The existence of an association of the level of functionality and the degree of gonarthrosis can be reflected in the application of adequate rehabilitating treatment and to indicate whether the rehabilitating treatment that is carried out is adequate, thus improving the quality of life of former athletes with gonarthrosis. Osteoarthritis, or wear and tear of the knee joint, is a painful, non-inflammatory, irreversible degenerative condition of the knee joint caused by wear and tear of the joint cartilage (Mesfar \& Shirazi-Adl, 2005; Chao et al., 1983).

Osteoporosis (also called osteoarthrosis -OA-) is a degenerative joint disease characterized by a progressive deterioration of hyaline cartilage combined with synovial and subchondral bone disorders, In the rodilla, also known as gonarthrosis, is a degenerative condition that occurs when changes occur in the mechanical properties of the cartilage and subchondral bone, according to the degree to which such a condition is found generates levels of limitation of functionality by affecting physical function through the presence of pain and stiffness, which in former athletes who suffer from it, reduces the quality of life interfering in their professional and working life. The research presented coincides with similar studies (Nancy, 2017; Madaleno et al., 2018; Pihl et al., 2003).

Sports practice, whether in competition or not, is subject to the eventuality of suffering injuries of different types that affect the whole of the musculoskeletal system and of which they are part, in addition to the bones, muscles, ligaments, tendons, cartilage, synovial membrane or bursas. Special mention should be made to the knee, as injuries to them can lead to more serious problems and can become especially serious. Sports injuries can be classified into acute and chronic. Acute injuries occur suddenly, such as fractures or sprains, and their most characteristic symptoms are sudden pain, inflammation, and difficulty movement. On the contrary, chronic lesions have a slower development, as they occur by the repetition of the same movement over a long time, as is the case of osteoarthritis in the knees by the overuse of the joint. Chronic injuries also cause inflammation and often cause pain even when you're at rest.

The main causes of osteoarthritis of the knee are Trauma during sports and recreational activities, overload from hard physical work, a congenital deformity of joints metabolic disorders, overweight. The knee joint joins the femur with the tibia. The ends of both bones are covered with cartilage and are held together by a joint capsule. Muscles, ligaments, and tendons ensure the stability of the knee joint. The reason for the high frequency of knee osteoarthritis, compared to other joints of the body, is because the knee is a "load" joint, that is, it has to bear the weight of the body and the objects we carry, when we stand or when we move walking, running, climbing or lowering stairs. The femur, tibia, patella, inside the knee all these bones are coated with cartilage, which serves to prevent the rubbing of bone with bone in the movements of the knee, facilitating the slipping and cushioning the blows (Burr, 2004; Fahlgren et al., 2001).

It is precisely the wear and tears over the years and the aging of the cartilage, which gives rise to osteoarthritis, being premature in athletes who start from a very early age where they do not possess the physical fullness, the necessary bone maturation, not defined to face competitive events of magnitude, who suffer strong physical and psychological pressures when exposed to the rigorous demand of sports training; Finally the consequence is premature wear and tear of the components of the osteomyarticular system if the fundamental role of joints is taken into account throughout the body. Excessive physical exercise. Other times knee osteoarthritis occurs as a result of a previous joint injury or abnormality such as injuries to the meniscus, ligaments, or joint bone, following intraarticular bone fractures. In Cuba there is a high prevalence of joint knee conditions, affecting almost all people over the age of 60 , consulting bibliographies we see that about $60 \%$ of injuries in sport correspond to the soft tissues of the osteomyarticular system and of them, between 40 and $50 \%$ have their origin in overuse, (repetitive microtrauma), in the case of sport one of the causes that condition the appearance of osteoarthrosis (Nancy, 2017; Daniels et al., 1986; Fader et al., 2014; Hamilton et al., 2015). According to published results of regenerative therapy and its relationship with effectiveness and effectiveness, it was applied considering benefiting former athletes who are research patients, in which there is already an important joint commitment (Hernandez \& Anillo-Badía, 2016; Mifune et al., 2013; Usas \& Huard, 2007). 


\section{Materials and Methods}

A therapeutic intervention study was conducted on 17 ex-athlete patients between the ages of 18 to 70 , carriers of knee osteoarthritis who were implanted with regenerative therapy treatments at the Provincial Center of Sports Medicine of Santiago de Cuba. Total population universe 17 ex-athletes, taking as sample 14, to evaluate variables of responses to the treatment of therapeutic exercises program applied to the studied population, which provide strengthening to the thigh muscle groups, stability, flexibility, and improve mobility for the knee joint. The information was obtained from the clinical histories of patients formed for research, the percentage statistical calculation was used for the analysis and interpretation of results, determining the improvement time in the beginning before treatment, 1, 3- and 6-months post-treatment.

The following variables were evaluated:

Mensuration muscular (Yves, 2002)

Measurement: Measurement of muscle volume that allows us to identify the degree of atrophy and the correct evaluation of a patient with muscle weakness.

To examine the patient's muscle volume, we should:

1) Measure the total length of the segment being analyzed, taking 2 reference points (one proximal and one distal) anatomical accident.

2) Mark below the proximal reference point 5 or $7 \mathrm{~cm}$. And above the distal point of 5 or $7 \mathrm{~cm}$. The proximal mark gives what is called the proximal perimeter and the distal mark gives the distal perimeter.

3) The midpoint is the division between two of the bone lengths between the proximal and distal points, this is what is called the midpoint of the segment.

This test is performed with a tape measure at the proximal, mid, and distal points circumferentially. For physical alterations, according to mensuration, the following categories were evaluated: Unilateral thigh atrophy: A single affected thigh, Bilateral thigh atrophy: Both thighs affected.

Muscle balance or muscle balance techniques of Daniels \& Worthingham for bending and extension of the knees. (Daniels \& Worthingham, 2003)

Muscle balance techniques. Muscle test: It is a simple method, very useful and takes care of 5 to 20 minutes, it is used for the evaluation of strength and function of muscles as fundamental components of movement and physical performance. Classic muscle balance techniques use manual evaluation methods.

Numerical score: Qualitative score:

$5 \operatorname{Normal}(\mathrm{N})$

4 Good (B)

3 Acceptable $(\mathrm{A})$

2 Deficient (D)

1 Vestige $(\mathrm{V})$

0 Null (no activity) (0)

Muscle grade 5 (Normal): muscle group complete the range of motion against maximum resistance.

Muscle grade 4 (Good): muscle group capable of performing a complete range of motion against gravity and tolerating strong endurance. The muscle "gives way" somewhat in its limit position with maximum resistance. Muscle grade 3 (Acceptable): muscle group can complete the range of motion only against resistance of gravity. No resistance.

Muscle grade 2 (Deficient): muscle group performs the full range of motion in a position of minimum gravity, the horizontal plane of movement is described.

Muscle grade 1 (Vestigio): the examiner can detect, visually or by palpation, some contractile activity in one or more of the muscles participating in the scanned movement (provided that the muscle is shallow enough to

Abad, L. N., Vidal, V. R., \& Sabatés, H. R. R. (2020). Gonoarthrosis in former athletes treated which regenerative therapy and therapeutic exercise program. International Journal of Health Sciences, 4(2), 1-9. https://doi.org/10.29332/ijhs.v4n2.426 
feel it), can also see or feel the tension of the tendon when the patient tries to perform the movement, but there is nobody movement in that minimal contractile activity.

Muscle grade 0 (Null): muscle group is shown lacking activity to palpation or visual inspection.

For the result of the manual muscle balance the following categories were evaluated:

Muscle balance or muscle balance techniques of Daniels \& Worthingham for knee extenders composed mainly of the muscle groups of femoral or crural quadriceps: (Straight anterior thigh, vast inner, vast external).

Muscle balance or muscle balance techniques of Daniels \& Worthingham for knee flexors. composed of muscle groups called popliteal: (Femoral or crural biceps, Semimembranous, Semitendinous).

Program therapeutic exercises of strengthening, stability, flexibility, and improvement of mobility (Ponce, 2017), shown in Table 1.

The quadriceps muscle is the most powerful in the whole body, in addition to the bulkiest. And rightly so, because it's in charge of holding our whole body, just by testing standing up. It helps us to walk, jump, run, dance, swim, and any movement that involves moving our legs.

Increased quadriceps muscle training, includes being able to have more range of motion, strength, speed, and power in the legs and, consequently, improve in each of the fields: swimming better, running faster, climbing higher.

The realization of an exercise program favors the strengthening of the knee muscles, providing stability, flexibility. You will improve in pain and your mobility.

\section{Program therapeutic exercises applied as a therapeutic intervention:}

\section{Exercise No: 1}

Exercise: General Calisthenic Exercises

Distribution per week: 3 times/sem Tandas: Before the exercise program. Repetitions: -

Muscles: Everyone in the body in general.

Procedures: The physical therapist or trainer will be put to the side of the athlete to correct posture.

\section{Exercise No: 2}

Exercise: Lying face down, bending the knee, and holding the position for 5 seconds.

Distribution per week: 3 times/sem Tandas: 2Q Repeats: $10 \mathrm{R}$ each/knee

Muscles: Knee flexors. Poplites

Procedures: The physical therapist or trainer will be put to the side of the athlete to correct posture.

\section{Exercise No: 3}

Exercise: Push the knee to the ground to the full extent, and hold the position for 5 seconds.

Distribution per week: 3 times/sem Tandas: 2Q Repeats: $10 \mathrm{R}$ each/knee

Muscles: Knee flexors. Poplites

Procedures: The physical therapist or trainer will be put to the side of the athlete to correct posture.

\section{Exercise No: 4}

Exercise: Quadriceps Extenders:

Leg raised in extension, contract the thigh and keep it contracted for 5 seconds, the thigh still contracted, slowly descend to the ground and relax and change leg.

Sitting stretching the leg affects forward, tapping the foot, in the same position keep leg stretched and tap forward and back.

Distribution per week: 3 times/sem Tandas: 2Q Repeats: $10 \mathrm{R}$ each/knee

Muscles: Knee extenders. Femoral or crural quadriceps

Procedures: The physical therapist or trainer will be put to the athlete's side to correct posture

\section{Exercise No: 5}

Exercise: foot, legs separated to the width of shoulders, flex knees, with arms forward we lower until the thigh is completely perpendicular to the leg, we go up slowly repeat. 
Distribution per week: 3 times/sem Tandas: 2Q Repeats: $10 \mathrm{R}$ each/knee

Muscles: Knee extenders. Femoral or crural quadriceps

Procedures: The physical therapist or trainer will be put to the athlete's side to correct posture

Exercise No: 6

Exercise: Standing your feet together we take a big step where we place the foot, we tilt our body forward, bending the extended knee and the other leg as well.

Distribution per week: 3 times/sem Tandas: 2Q Repeats: $10 \mathrm{R}$ each/knee

Muscles: Knee extenders. Femoral or crural quadriceps

Procedures: The physical therapist or trainer will be put to the athlete's side to correct posture

Table 1

Therapeutic physical exercise program for knee flexors and extenders and the distribution of this work content

\begin{tabular}{|c|c|c|c|c|c|c|c|c|}
\hline \multirow[t]{2}{*}{$\begin{array}{l}\text { Program } \\
\text { Therapeutic } \\
\text { exercises }\end{array}$} & \multirow[t]{2}{*}{$\begin{array}{l}\text { Classification of } \\
\text { Knee Movement }\end{array}$} & \multirow[t]{2}{*}{ Muscles } & \multirow[t]{2}{*}{ Batches } & \multirow[t]{2}{*}{ Repetitions } & \multicolumn{4}{|c|}{$\begin{array}{c}\text { Distribution Per } \\
\text { Weeks (3 } \\
\text { Times/Sem) } \\
\text { Weeks }\end{array}$} \\
\hline & & & & & 1 & 2 & 3 & 4 \\
\hline $\begin{array}{l}\text { E.1. Exercises } \\
\text { Cgeneralallies }\end{array}$ & - & $\begin{array}{l}\text { All. The } \\
\text { body in } \\
\text { general. }\end{array}$ & $\begin{array}{l}\text { Before the } \\
\text { exercise } \\
\text { program }\end{array}$ & - & $X$ & $\mathrm{X}$ & $\mathrm{X}$ & $\mathrm{X}$ \\
\hline $\begin{array}{l}\text { E.g. Lying face } \\
\text { down, bend the } \\
\text { knee and hold the } \\
\text { position for } 5 \\
\text { seconds. }\end{array}$ & Knee Flexorss & Poplíteos & $2 \mathrm{~T}$ & $10 \mathrm{R}$ each/knee & $\mathrm{X}$ & $\mathrm{X}$ & $\mathrm{X}$ & $\mathrm{X}$ \\
\hline $\begin{array}{l}\text { E.3. Push the knee } \\
\text { towards the } \\
\text { ground to the full } \\
\text { extent, and hold } \\
\text { the position for } 5 \\
\text { seconds }\end{array}$ & Knee Flexorss & Poplíteos & $2 \mathrm{~T}$ & $10 \mathrm{R}$ each/knee & $X$ & $\mathrm{X}$ & $\mathrm{X}$ & $\mathrm{X}$ \\
\hline $\begin{array}{l}\text { E.4. Quadriceps } \\
\text { Extensions }\end{array}$ & Kneesextenders & $\begin{array}{l}\text { Femoral or } \\
\text { crural } \\
\text { quadriceps }\end{array}$ & $2 \mathrm{~T}$ & $10 \mathrm{R}$ each/knee & $\mathrm{X}$ & $\mathrm{X}$ & $\mathrm{X}$ & $\mathrm{X}$ \\
\hline E.5. Squats & Knee extenders & $\begin{array}{l}\text { Femoral or } \\
\text { crural } \\
\text { quadriceps }\end{array}$ & $2 \mathrm{~T}$ & $10 \mathrm{R}$ each/knee & $X$ & $\mathrm{X}$ & $\mathrm{X}$ & $\mathrm{X}$ \\
\hline E.6. Strides & Knee extenders & $\begin{array}{l}\text { Femoral or } \\
\text { crural } \\
\text { quadriceps }\end{array}$ & $2 \mathrm{~T}$ & $10 \mathrm{R}$ each/knee & $\mathrm{X}$ & $\mathrm{X}$ & $\mathrm{X}$ & $\mathrm{X}$ \\
\hline
\end{tabular}

Abad, L. N., Vidal, V. R., \& Sabatés, H. R. R. (2020). Gonoarthrosis in former athletes treated which regenerative therapy and therapeutic exercise program. International Journal of Health Sciences, 4(2), 1-9. https://doi.org/10.29332/ijhs.v4n2.426 


\section{Results and Discussions}

The graph in Figure 1 shows the distribution of physical alterations according to the measuring of the muscular trosfism of the affected thighs. No. 14. Of the 14 former total athletes of the population investigated with knee gonoarthrosis treated with regenerative therapy according to the distribution of physical alterations according to the measuring of the muscular trosfism of the affected thighs, At 6 months bilateral thigh atrophy predominated for $14.2 \%$, over unilateral atrophy for $7.1 \%$, less than $21 \%$ had affected thigh atrophy at the end of 6 months after treatment with an applied therapeutic exercise program (Fathoni et al., 2018; Marshall \& Murphy, 2005; Huang et al., 2003; Smeets, 2009). According to revised literature (Nancy, 2017), they argue that the involvement of one or both thigh muscles make no difference in predominance between them and the other in terms of atrophy, may or may not be affected together or separately, which is common the involvement of both knees, especially in sports females where they show a higher incidence of knee injuries, in various theories the existence of anatomical differences, differences in joint laxity, hormone levels, proprioceptive sensitivity, and training techniques have been suggested. They have a higher laxity in the knee and show a lower joint proprioceptive sensitivity than men.

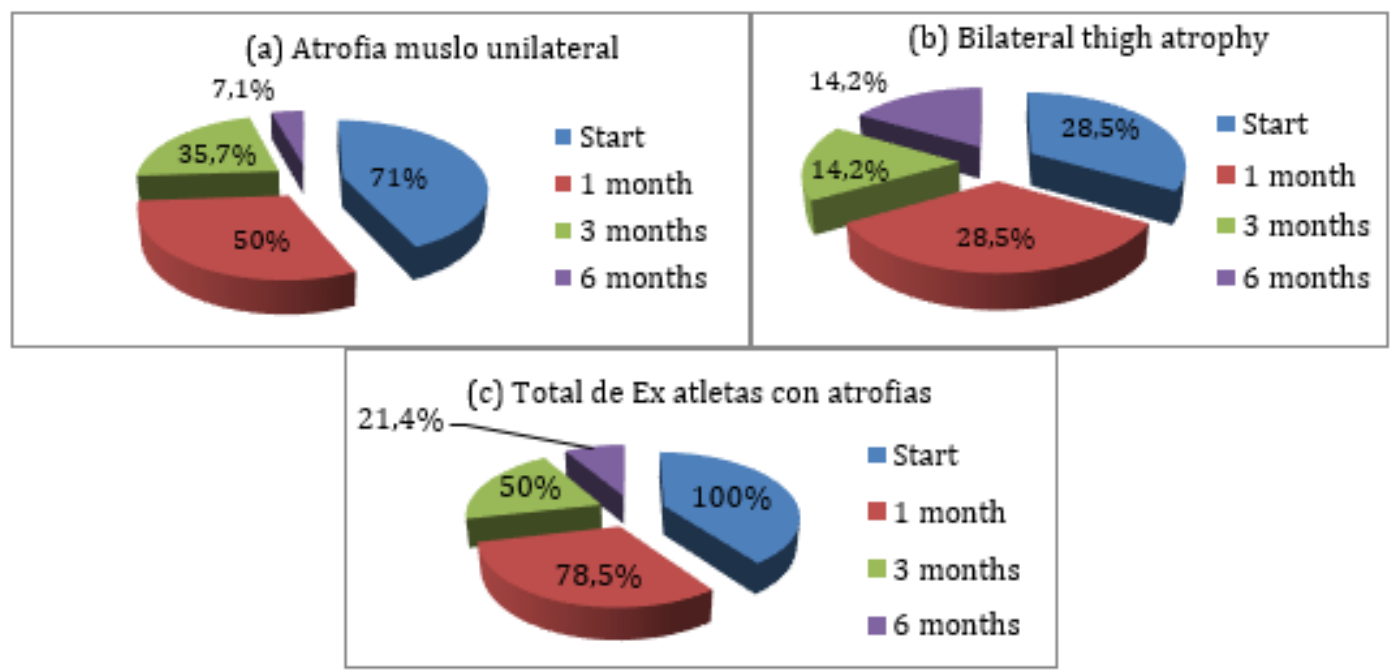

Figure 1. Distribution of physical alterations according to mensuration of muscle trosfism of the thighs affected unilateral or bilateral. No. 14

The graph in Figure 2 shows the distribution of Daniels \& Worthingham muscle balance or muscle balance techniques for flexors and knee extenders. No. 14. At the end of the 6 months post-treatment with applied therapeutic exercises program; $71.4 \%$ showed recovery of muscle strength with grade 5 (normal) muscle notes for the muscle group of the popliter knee flexors, and $85.7 \%$ with grade 5 muscle notes (normal) for the muscular group of femoral or crural quadriceps those involved in the extension of the knees. It coincides with revised literature (Daniels \& Worthingham, 2003), in this one proposes that, the more training of quadriceps muscles, includes being able to have more range of motion, strength, speed, and power in the legs and, consequently, improve in each of the fields of sport, work and daily. 


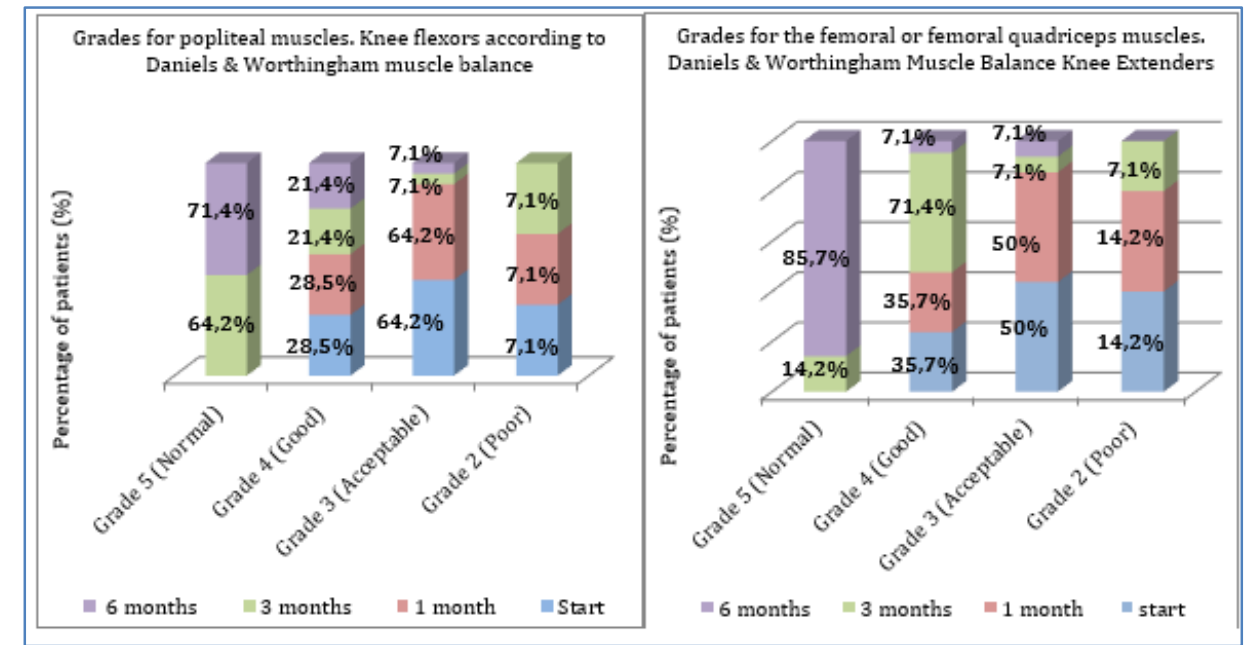

Figure 2. Distribution of muscle balance or muscle balance techniques of Daniels \& Worthingham for flexors and knee extenders. No. 14

\section{Conclusion}

The application of the therapeutic alternative with rehabilitating exercises to the population of former athletes with knee gonoarthrosis, who were previously treated with regenerative therapy and who were accompanied by muscle atrophy of the thigh, in addition to muscle weakness; $21.4 \%$ maintained this condition, the rest were recovered, as well as $71 \%$ or more, showed recovery of muscle strength with Grade 5 muscle notes (Normal) in the evolutions of muscle balance techniques or Daniels \& Worthingham tests for muscles involved in the flexion and extension of the knees, this provides the strengthening.

Acknowledgments

We are grateful to two anonymous reviewers for their valuable comments on the earlier version of this paper.

Abad, L. N., Vidal, V. R., \& Sabatés, H. R. R. (2020). Gonoarthrosis in former athletes treated which regenerative therapy and therapeutic exercise program. International Journal of Health Sciences, 4(2), 1-9. https://doi.org/10.29332/ijhs.v4n2.426 


\section{References}

Burr, D. B. (2004). Anatomy and physiology of the mineralized tissues: role in the pathogenesis of osteoarthrosis. Osteoarthritis and cartilage, 12, 20-30. https://doi.org/10.1016/j.joca.2003.09.016

Chao, E. Y., Laughman, R. K., Schneider, E., \& Stauffer, R. N. (1983). Normative data of knee joint motion and ground reaction forces in adult level walking. Journal of biomechanics, 16(3), 219-233. https://doi.org/10.1016/0021-9290(83)90129-X

Daniels, L. \& Worthingham, C. A. (2003). Muscle testing Techniques of Manual Examination Helen J. Hislop y Jacqueline Montgomery. 7th d. España. Elsevier.

Daniels, L., Williams, M. \& Worthingham, C.A. (1986). Muscle Testing: Techniques of Manual Examination, 5th ed. Philadelphia: WB Saunders.

Fader, R. R., Mitchell, J. J., Traub, S., Nichols, R., Roper, M., Dan, O. M., \& McCarty, E. C. (2014). Platelet-rich plasma treatment improves outcomes for chronic proximal hamstring injuries in an athletic population. Muscles, ligaments and tendons journal, 4(4), 461.

Fahlgren, A., Andersson, B., \& Messner, K. (2001). TGF- $\beta 1$ as a prognostic factor in the process of early osteoarthrosis in the rabbit knee. Osteoarthritis and cartilage,9(3), 195-202. https://doi.org/10.1053/joca.2000.0376

Fathoni, A., Adiputra, N., Pangkahila, J. A., \& Adiatmika, I. P. G. (2018). Reduction of levels postprandial blood glucose on medium intensity physical exercise in intervals and continues. International Research Journal of Engineering, IT \& Scientific Research, 4(6), 10-32. https://doi.org/10.21744/irjeis.v4n6.331

Hamilton, B., Tol, J. L., Knez, W., \& Chalabi, H. (2015). Exercise and the platelet activator calcium chloride both influence the growth factor content of platelet-rich plasma (PRP): overlooked biochemical factors that could influence PRP treatment. Br J Sports Med, 49(14), 957-960. http://dx.doi.org/10.1136/bjsports-2012-091916

Hernández-Hernández, A., \& Anillo-Badía, R. (2016). Regenerative medicine and sports medicine, a successful integration: introduction and advances in Cuba. Revista Cubana de Hematología, Inmunología y Hemoterapia, 32(3), 285-288.

Huang, M. H., Lin, Y. S., Yang, R. C., \& Lee, C. L. (2003, June). A comparison of various therapeutic exercises on the functional status of patients with knee osteoarthritis. In Seminars in arthritis and rheumatism (Vol. 32, No. 6, pp. 398-406). WB Saunders. https://doi.org/10.1053/sarh.2003.50021

Madaleno, F. O., Santos, B. A., Araújo, V. L., Oliveira, V. C., \& Resende, R. A. (2018). Prevalence of knee osteoarthritis in former athletes: a systematic review with meta-analysis. Brazilian journal of physical therapy, 22(6), 437-451. https://doi.org/10.1016/j.bjpt.2018.03.012

Marshall, P. W., \& Murphy, B. A. (2005). Core stability exercises on and off a Swiss ball. Archives of physical medicine and rehabilitation, 86(2), 242-249. https://doi.org/10.1016/j.apmr.2004.05.004

Mesfar, W., \& Shirazi-Adl, A. (2005). Biomechanics of the knee joint in flexion under various quadriceps forces. The knee, 12(6), 424-434. https://doi.org/10.1016/j.knee.2005.03.004

Mifune, Y., Matsumoto, T., Takayama, K., Ota, S., Li, H., Meszaros, L. B., ... \& Huard, J. (2013). The effect of platelet-rich plasma on the regenerative therapy of muscle derived stem cells for articular cartilage repair. Osteoarthritis and Cartilage, 21(1), 175-185. https://doi.org/10.1016/j.joca.2012.09.018

Nancy, D. D. (2017). Lesiones deportivas [Internet]. National Institute of Arthritis and Musculoskeletal and Skin Diseases. [Citado 5 de abril de 2019]. Disponible en: https://www.niams.nih.gov/es/informacion-desalud/lesiones-deportivas.

Pihl, E., Zilmer, K., Kullisaar, T., Kairane, C., Pulges, A., \& Zilmer, M. (2003). High-sensitive C-reactive protein level and oxidative stress-related status in former athletes in relation to traditional cardiovascular risk factors. Atherosclerosis, 171(2), 321-326. https://doi.org/10.1016/j.atherosclerosis.2003.08.015

Ponce, A. (2017). Knee osteoarthritis exercises. Rheumatological Clinic.https//:www.doctorponce.com.

Smeets, R. J. (2009). Do lumbar stabilising exercises reduce pain and disability in patients with recurrent low back pain?. Australian Journal of Physiotherapy, 55(2), 138. https://doi.org/10.1016/S0004-9514(09)70046-7

Usas, A., \& Huard, J. (2007). Muscle-derived stem cells for tissue engineering and regenerative therapy. Biomaterials, 28(36), 5401-5406. https://doi.org/10.1016/j.biomaterials.2007.09.008

Yves, X. (2002). Vademecum of Kinesiotherapy and Functional Re-education; Technique, Pathology and Treatment Indications- 4a.ed 30 Reprint - Buenos Aires: El ateneo. 


\section{Biography of Authors}

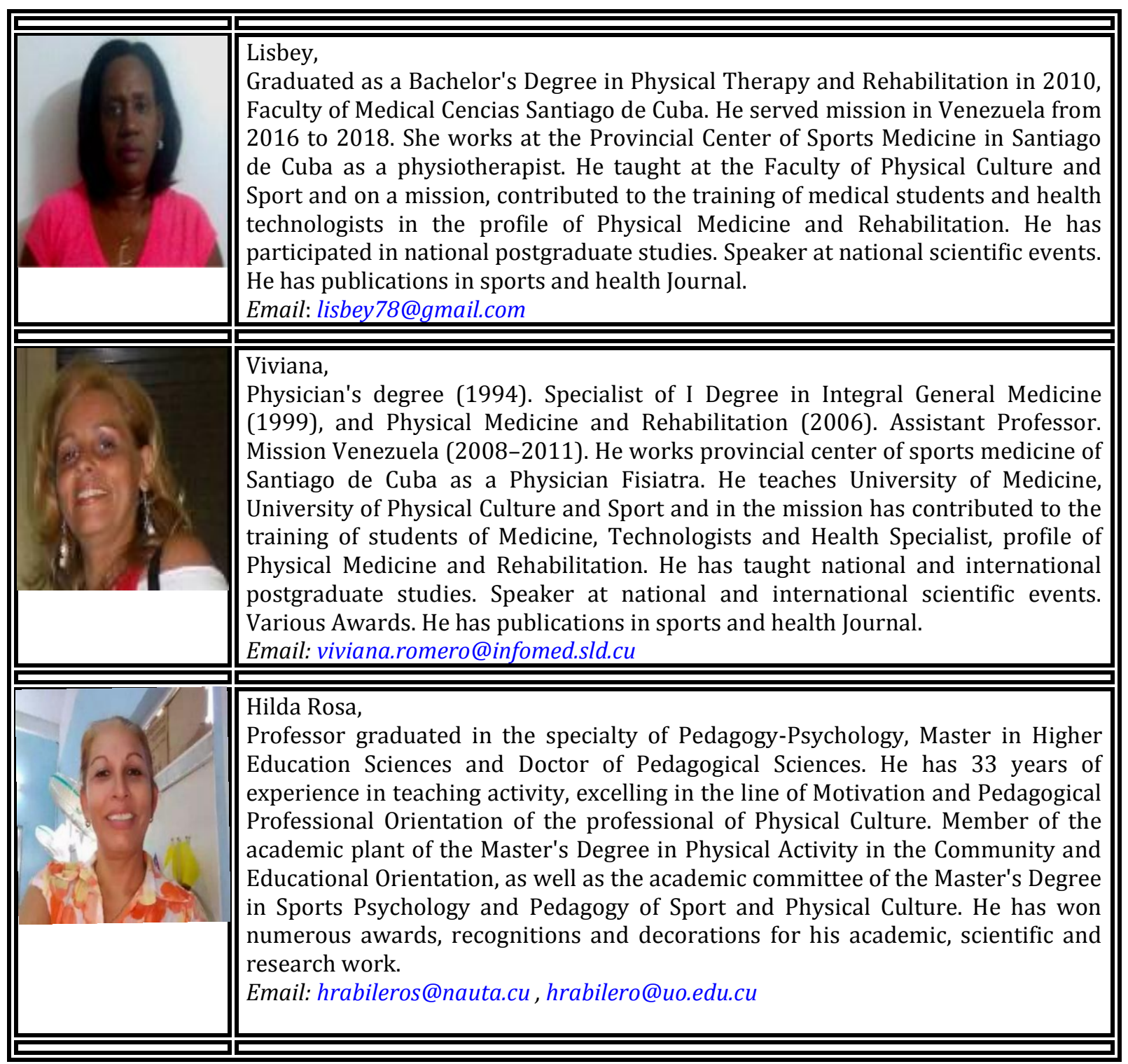

Abad, L. N., Vidal, V. R., \& Sabatés, H. R. R. (2020). Gonoarthrosis in former athletes treated which regenerative therapy and therapeutic exercise program. International Journal of Health Sciences, 4(2), 1-9. https://doi.org/10.29332/ijhs.v4n2.426 